\title{
BREVE ANÁLISE DAS AÇÕES, LIMITES E OS OBSTÁCULOS VIVENCIADOS NO COTIDIANO DOS PROFISSIONAIS ATUANTES DO CONSELHO TUTELAR NA CIDADE DE JATAÍ - GOIÁS
}

\author{
LIMA, Eliane Assis ${ }^{1}$ \\ COSTA, Elis Regina ${ }^{2}$
}

\section{RESUMO}

A presente investigação foi de natureza descritiva e possuía como objetivo analisar as ações, limites e os obstáculos vivenciados no cotidiano dos profissionais atuantes do conselho tutelar na cidade de Jataí - Goiás. Os participantes foram dois integrantes do Conselho Tutelar de Jataí, Goiás no ano de 2012, um do gênero do sexo masculino e outro feminino, ambos possuía, Graduação (Geografia e Pedagogia), com faixa etária de 31 e 32 anos respectivamente. Fez-se uma entrevista com participantes sobre sua atuação. Os resultados mostraram que os conselheiros possuem bastante clareza sobre como deve ser sua atuação junto as crianças e adolescentes da região. Ambos relataram que, não ha esclarecimentos de suas ações e deveres junto ao público em geral e as famílias em relação as suas funções. Tal desconhecimento bem como as cobranças por ações imediatas os constrangem. Os dados apontam falta de uma estrutura física e humana que lhe dêem suporte para um trabalho de qualidade. Ambos sentem o desamparo do sistema para o problema da violência contra criança e adolescente.

Palavras chaves: Conselho tutelar. Violência contra crianças e adolescentes. Estatuto da criança e do adolescente.

\section{ANALYSIS OF STOCK SHORT, LIMITS AND OBSTACLES IN DAILY LIFE OF EXPERIENCED GUARDIANSHIP COUNCIL PROFESSIONALS WORKING IN JATAÍ CITY - GOIÁS}

\begin{abstract}
This research was descriptive in nature and had to analyze the actions, limits and obstacles experienced in the daily lives of working professionals the child protection agency in the city of Jataí - Goiás. The participants were two members of the Guardian Council of Jataí, Goiás

\footnotetext{
${ }^{1}$ Pedagoga pela Universidade Federal de Goiás - Regional Jataí, E-mail: elianelimapedagogia@hotmail.com

${ }^{2}$ Psicóloga. Doutora em Educação pela Universidade Estadual de Campinas. Professora Adjunta da Faculdade de Educação da Universidade Federal de Goiás - Regional Catalão. E-mail: elisreginacosta@ yahoo.com.br
} 
in the year 2012, a male gender and one female, both had, Graduation (Geography and Pedagogy), aged between 31 and 32 years respectively. There was an interview with participants about their performance. The results showed that the directors have very clear about how it should be their work with children and adolescents in the region. Both reported that there is no explanation of their actions and duties to the public in general and families in relation to their functions. Such ignorance and charges for immediate action constrain them. The data indicate lack of physical and human structure to give you support for quality work. Both feel the system helplessness to the problem of violence against children and adolescents.

Keywords: Child Protection Council. Violence against children. Child and Adolescent Statute.

\section{INTRODUÇÃO AO TEMA: SENTIMENTO DE INFÂNCIA E A CONCEPÇÃO DE FAMÍLIA}

O sentimento de infância constituiu-se ao longo dos séculos, e foi a partir do seu lugar determinado na família e na escola, que ocorreu essa evolução e transformação. Uma construção lenta de afetos que se estreitaram nas relações sociais. De acordo com Ariés (1981) o sentimento de infância pode ser percebido no final do século XVI, mas sobretudo no século XVII. Com as transformações sociais e as reformas religiosas, essas mudanças aconteceram sob diferentes aspectos. A sociedade anteriormente não nutria o sentimento de afeto para com a criança. Aries (1981) percebe nas artes a ausência dos sentimentos em relação á infância e de como este ocorreu ao longo da historia. A criança era uma projeção do adulto em miniatura, e assim ela tão logo adquiria sua independência física, por volta dos sete anos de idade se juntava aos adultos, e participava de todas as atividades, incluindo orgias. Ainda de acordo com Ariés, o sentimento de paparicação foi o primeiro a ocorrer e este com a família, um passo importante para o processo que sucedeu a organização da família e do afeto para com a criança. As transformações ao longo dos séculos XVIII, XIX e XX correspondem a períodos da construção e das percepções, em relação ao ser infante, estudados e discutidos por autores. No decorrer desses séculos criam-se outros valores e a criança ocupa um papel principal na família. Ainda segundo Ariés (1981) essas concepções de valores resulta, ancorada na igreja, em uma preocupação com a educação que preparasse a criança para o universo adulto e para os negócios da família com o princípio da razão.

No Brasil devido a seu processo histórico de ocupação, constrói se uma sociedade desigual, neste sentido desde o inicio de sua civilização, a exploração, o abandono e a 
diferenciação das crianças em classes, são marcos da nossa história. Já na modernidade surge um termo usado para com as crianças desfavorecidas: menor, este institucionalizado pelo o sistema governamental. Com a elaboração do (ECA) Estatuto da Criança e do Adolescente de 1990, este termo deixa de existir. Diferente dos séculos passados, o sentimento de infância é visto de outro prisma, as transformações que ocorreram no mundo repercutem na infância e esta passa a ter direitos a partir da concepção de cidadão. Com o advento do sentimento de infância são elaboradas de leis que incubem as famílias, as escolas e o Estado de serem responsáveis pela criança e o adolescente. Nesse sentido lhe é específico uma visão articulada desse sentimento onde envolve o cuidar e o educar na intenção de sua total proteção. Há projetos, leis e instituições que amparam e garantem os direitos as crianças e adolescentes, mas infelizmente elas não as protegem de sofrerem com a violência, e a miséria, esta última também não deixa de ser uma violência, mas do sistema. Muitas nascidas e criadas em famílias desfavorecidas de capital, são vitimas desse sistema e muito cedo partem para a marginalidade, a infância e suas etapas até atingir a idade adulta, para esse público é uma coisa distinta, alheia a sua realidade. Assim sendo as medidas implantadas pelo (ECA) estatuto da Criança e do Adolescente, elas necessitam ser eficazes e democráticas e de forma integra.

É fato que são vários os fatores causadores da violência, dentre eles são: o econômico, político e o cultural. Refletindo no âmbito familiar, independente de classe social, ela se tornou um problema da sociedade, fazendo assim surgirem leis e decretos da parte das políticas publicas visando seu enfrentamento. Apesar do avanço, a violência ainda é pouco discutida, e um muita explorada pela mídia. De acordo com Bueno (1996) "violência é o ato de violentar, definida como toda ação que pode ferir a vida intencionalmente de natureza física e/ou mental, e ela é caracterizada como imposição da força física e psicológica' (p679). Ao fazer um estudo mais acurado verifica-se que a estrutura social do homem vem sendo construída ao longo da história da humanidade e a violência infelizmente ainda acompanha essa evolução. tendo por base o fenômeno da violência em nossa sociedade e a atuação do conselho tutelar, o presente estudo propôs os seguintes problemas de pesquisa: Como os Conselho Tutelar, que é um dos órgãos responsáveis por zelar das crianças e adolescentes no município de Jataí - Goiás, tem vivenciado as ações, limites e obstáculos face aos casos atendidos nesta realidade? 


\section{JUSTIFICATIVA}

A sociedade ainda não confere a importância devida, a violência contra crianças e adolescentes. São vários os tabus impregnados neste tema, mas aos poucos o silêncio está sendo quebrado. Dessa forma, a violência cometida contra crianças e adolescentes vem cada vez mais sendo denunciados. È necessário que a sociedade se interesse pela realidade vivenciada por crianças e adolescentes, porque são indivíduos em formação e vulneráveis aos adultos. A presença da família é um fator determinante para a formação de sua personalidade e a sua realização escolar, um lar harmonioso, equilibrado e amoroso é o que necessitam as crianças e adolescentes, é importante que eles compreendam esses valores para que desenvolvam saudáveis. Dessa forma é preciso repensar os valores educativos que as famílias estão reproduzindo, regras, disciplinas e a participação dos pais são fundamentais para que a criança e o adolescente desenvolvam e se tornem adultos conhecedores de seus direitos e deveres. As crianças e os adolescentes ao ter, seus direitos ameaçados e violados, tem o amparo legal do Estatuto da Criança e do adolescente ( ECA ) garantindo a proteção integral em lei a elas.

Desde os tempos mais remotos a violência se faz presente na humanidade e investigar de maneira aprofundada como o Conselho Tutelar atua diante dessa realidade sofrida pelas crianças e adolescentes na cidade de Jataí,Goiás é o objetivo desta investigação. Ao investigar as ações do Conselho Tutelar dentro da sociedade da cidade de Jataí, Goiás, mais especificamente pretendia-se compreender as leis e ações utilizadas neste município, verificando quais as medidas diante do fenômeno da violência, e tentar compreenda-las na sua totalidade, se atentando para a importância das mesmas e a proteção desse público vulnerável. Ao fazer um estudo e levantar dados sobre este fenômeno, procura-se ter uma visão mais articulada do trabalho do Conselho Tutelar como um dispositivo de controle e se o mesmo cumpri o que estar determinado em lei. Neste sentido a presente pesquisa pretende ampliar os conhecimentos a respeito deste tema, em uma realidade pouco explorada em nível nacional. Pretende-se contribuir por meio deste estudo, pois ao se estudar e divulgar suas ações, as confusões e interpretações erradas por parte população em relação a atuação do conselho tutelar diminuem. Ações como palestras organizadas pelo poder público, propaganda realizada pela mídia são ações que vem aos poucos ocupando espaço e diante destes fatos é relevante que se faça uma reflexão sobre os aspectos culturais, e seus valores. 


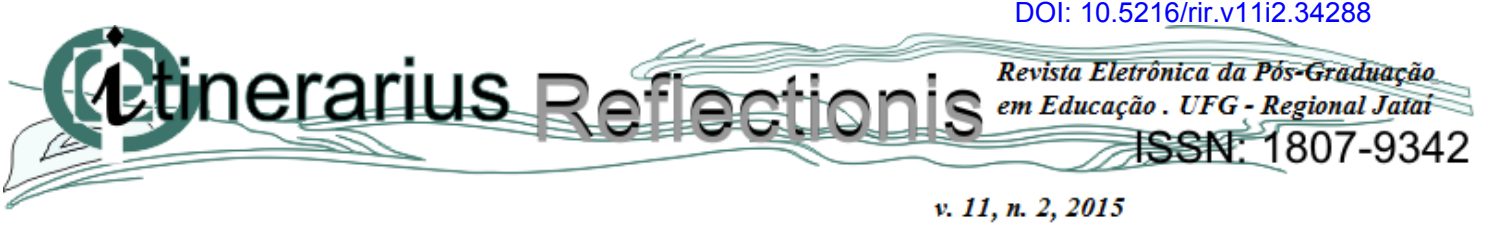

Outra contribuição é conscientizar os educadores do seu papel enquanto agente de denúncias. As crianças ao serem ameaçados, devem ter no professor como zelador e protetor, com a função legal de zelar pela integridade metal e intelectual das mesmas e tem um papel importante na ação de orientar e denunciar quaisquer que seja as ações sofridas a criança e ao adolescente. Sua omissão e negligência acarreta danos a crianças em níveis psicológicos e físicos. Ao levantar esta questão foi no sentido de orientar para a reflexão das práticas pedagógicas, sobre as manifestações e atuações no cotidiano escolar, principalmente na educação infantil, o educador como intermediador do conhecimento e formador de cidadãos, deve ter uma formação continuada dos conhecimentos sobre as formas de enfrentamento da violência na infância e adolescência,uma questão social e portanto educativa.

O presente estudo aborda a temática da violência, e uma análise das ações, limites e os obstáculos vivenciados no cotidiano dos profissionais atuantes do Conselho Tutelar na cidade de Jataí, Goiás bem como o enfrentamento da violência contra crianças e adolescentes bem como a prevenção contra a violência física, psicológica e social.

\section{REFERENCIAIS TEÓRICOS}

\subsection{A Violência Contra As Crianças E Os Adolescentes}

Segundo Odalia (1985), a violência, não é evidente por si mesma em toda as suas manifestações, as vezes podendo ser tão sutil que passa despercebida ao convívio humano, e se manifestam como naturais e normais. A sociedade vive um momento de normalidade sendo assim a violência sexual tanto quanto qualquer outra é tratada com descaso e velada. Diante da realidade não é relevante somente esses aspectos, mas se faz necessário observar os valores e crenças impregnados na sociedade, no que é determinado e imposto ao homem. Vivemos em uma sociedade pós moderna, e ela não deveria mais tolerar atos de violência contra crianças e adolescentes,é no mínimo uma afronta que esta ainda ocorra.

Segundo Marques (1982) "não devemos nos esquecer de que foi o silêncio e a cumplicidade das chamadas grandes potências que estimularam as carreiras de Hitler, Stálin, Franco...", é necessário que haja respeito aos direitos humanos e que não haja mais tolerância para quaisquer tipo de barbárie. A violência contra crianças e adolescentes era ocultada e disfarçada até bem pouco tempo atrás, nos dias atuais,devido as leis implantadas e as ações dos órgãos competentes, aos poucos, ela esta sendo denunciada e discutida, embora saibamos 
que ainda há um índice de violência contra crianças e adolescentes elevado e muito mais freqüente do que possamos imaginar, a divulgação e as denuncias ainda não obtiveram resultados satisfatórios e merecidos. Para Marques, o sistema é corrompido e a população fica desprotegida, e a mercê deste sistema.

O amor, carinho e afeto na família, o amor á vida, como valor fundamental do homem, o amor fraterno nas relações sociais e econômicas, o amor que respeita o próximo, está sendo substituído pelos valores da sociedade materialista de consumo, permissiva e corrupta, onde o que importa é o poder, a qualquer preço, principalmente ás custa dos fracos e oprimidos, o dinheiro como fim último da vida e como meio para se atingir qualquer objetivo a ser consumido, de conformidade com os gostos do momento.

As afirmações acima, nos levam a crer que o processo da civilização humana, por mais que pensemos na sua evolução ainda, permanece arcaico, e diante do mesmo, pode - se dizer que o sujeito desenvolve de acordo com seu meio, e suas atitudes serão resultados da forma que lhe é imposta, tanto pode desenvolver a passividade quanto a agressividade. Neste contexto a violência se propaga de diferentes formas e maneiras na sociedade, e pode ser classificada de: biológica, social e econômica. Pode ainda ser enquadrada em diversas categorias, como violência física, Psicológica e sexual. A violência Física se caracteriza por atos violentos de agressão de maneira intencional e moral; que fere a integridade do individuo; Já a violência Psicológica envolve rejeição, desrespeito, humilhação, manipulação, exploração, isolamento, insulto, pode ser qualquer meio que cause danos psicológicos; Por último temos a violência sexual que pode ser física, erótica e sexual, não desejadas, fazendo se valer da força, compreendida como qualquer conduta indesejada.

É bastante comum nas terapias a indicação de psicólogos para lidar com esses casos, e geralmente a família também é orientada a participar, na verdade são muitos os envolvidos, a vitima, a família, o agressor, e os profissionais como : Juiz, Conselho Tutelar, abrigos, profissionais da saúde, policia e outros, é preciso pensar também na punição do infrator e principalmente no cuidado para com a vitima, que ao sofrer a agressão, o ato de violência em si, ficam as marcas, os traumas. Alguns traumas são baixa auto-estima, agressividade, medo, culpa, ansiedade, e muitos outros, são medos que podem se arrastar para o resto da vida.

Sobre o Estatuto Da Criança e do Adolescente, dar-se-á ênfase á alguns artigos do mesmo que garante o bem estar físico e mental previsto em lei, o $2^{\circ}$ artigo "considera se que 
crianças, para o efeito da lei, a pessoa até doze anos de idade incompletos e adolescentes aquela entre doze e dezoito anos de idade. Parágrafo único. Nos casos expressos em lei, aplica se excepcionalmente este Estatuto ás pessoas entre dezoito e vinte anos." (Estatuto da criança e do adolescente, p.20)

A criança desde o seu nascimento necessita de cuidados tantos físicos e morais, e a presença do adulto é essencial para seu desenvolvimento. È no seio da família, de acordo com o Estatuto da Criança e do Adolescente (ECA, 1990) que se espera estabelecerem as relações básicas fundamentais de condutas, no meio social em que vive. Assim, o período de infância/adolescência é diretamente marcado por influencias vivenciadas pela criança no ambiente familiar (ou institucional, quando a instituição substitui a família (FERRARI, 2002.p.45) e instituição escolar, onde a criança convive com valores culturais diferentes. Não há um modelo pronto de família a ser seguido o que se requer é um ambiente saudável, cada qual com suas particularidades, então não discutirei a cerca deste aspecto tão particular e historicamente construído.

\subsection{Um Breve Apanhado Histórico dos direitos da criança e do adolescente no Brasil}

De acordo com Ferrari, desde as civilizações mais remotas as formas de tratamentos oferecidas as crianças, são as mais diversas possíveis, e foi o cristianismo que iniciou por caridade, obras que cuidassem de crianças abandonadas, esta situação durou até o final do século XIX. De 1924 a 1952 em Genebra e Viena, por meio das assembléias, intitula -se o bem estar da criança e do adolescente, e com isso garante e define no dia $1^{\circ}$ de junho, como o Dia Internacional da Criança, e em 20 de dezembro de 1959 a ONU declarou os Direitos da Criança, assim garantindo por lei a proteção a elas. No Brasil, o sistema governamental passa a ter consciência das crianças e adolescentes abandonados a partir do século XX, com a explosão demográfica, a população triplicou e mais de 50\% dela formada por crianças e jovens, assim o índice aumentou delas no trabalho fabril, abandonadas e delinqüentes nas ruas. Este fator mobilizou a sociedade, devido a elas ficarem sem proteção, sem nenhuma lei que as amparassem.

Segundo o Conselho nacional dos Direitos da Criança e do Adolescente (CONANDA), de 2001-2005, o primeiro projeto de lei foi apresentado no Brasil, em 1906 por Alcindo Guanabara, na intenção de ordem e higiene para com o ser infante e em 1927 o código de menores foi promulgado, com o nome Melo Matos, por ele ter sido o primeiro juiz 
de menores no país, foi na passagem da monarquia para a república que houve a explosão a Primeira República se une com a sociedade e o Estado e tomam atitudes disciplinares para com a criança e o adolescente. A fundação Nacional do Bem estar do Menor FUNABEM, a lei federal 4.513 de 01/12/1964 e a lei de 1.534 de 1967 a Fundação Estadual do Bem Estar do Menor, foram criadas e destinadas a tomarem para si as responsabilidades por via de programas a lidar com a marginalidade dessas crianças e adolescentes existentes na época, contudo, sem qualquer intenção de reintegração ou socialização, visando somente o bem estar físico. No entanto não havia uma visão articulada do poder público sobre os direitos da criança, nas suas ações, não havia um censo de moralidade, e os abusos sofridos para com a criança e o adolescente não obtiveram a atenção devida.

Foi a partir das preocupações com a moralidade, segundo o discurso da época de que a criança é o meio para o desenvolvimento do país, que surgiram alguns grupos filantrópicos e religiosos os quais criaram centros de apoios a criança e ao adolescente, com a finalidade de reintegrá-los a sociedade. Mesmo após tantos anos da aplicação das leis de proteção as crianças, estas ainda continuavam a sofrer abusos, e vítimas de maus tratos, incluindo o abuso sexual. Na visão de Ferrari, foi com o surgimento da psicologia e com os trabalhos de vários estudiosos como Piaget, que se ampliou a compreensão a respeito das conseqüências psicológicas da violência sobre o comportamento da criança abusada. Dessa forma na década de 1970 as primeiras denúncias, e publicações emergem sobre os abusos e agressões contra as crianças e 1979 o código sofre uma reformulação, mas continuando com a concepção como menor abandonado.

Em 1980 o fenômeno da violência contra crianças e adolescentes no Brasil passa a ser categoricamente estudado e discutido e em 1989 de acordo com a convenção sobre os direitos da criança, fica determinado que de 0 até 18 anos são garantidos seus direitos individuais e coletivos em lei. Em 13 de julho de 1990 é promulgada a lei de numero 8.069 o Estatuto da Criança e do adolescente ( ECA ), lei federal elaborada para proteger os direitos das crianças e dos adolescentes até então nomeados menor, passam a ser referidas pela nomenclatura criança e adolescente e tem garantidos em lei a integridade física e moral dos mesmos até tornarem-se cidadãos. Para as notificações dos casos de violência, ou qualquer situação que possa colocar a criança e o adolescente em risco, irregularidades que as envolva se faz necessário acionar o conselho tutelar, promotoria da infância e juventude, secretaria municipal de saúde, defensoria pública, pois a partir da vigência da nova lei, a polícia 


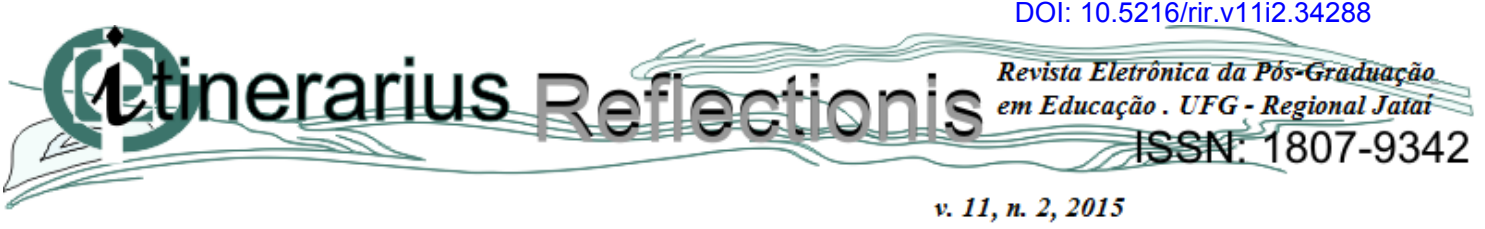

somente é acionada em casos extremos. Tais autoridades são essenciais a fim de tratar dos casos, contudo a comunidade também é responsável. O educador certamente tem uma posição privilegiada e sua contribuição é indispensável e necessária para consolidar e construir na instituição escolar em que atua, uma consciência reflexiva. O quanto antes, a criança e o adolescente receberem assistências, maiores as chances delas superarem a experiência negativa. Para que ocorra esse cenário se faz necessário a presença nos currículos conteúdos que abordem a temática da violência contra crianças e adolescentes de forma que os preparem para a percepção das evidencias de tal ato.

Em 1991 é promulgada a Lei nº11.549, que cria o conselho Estadual dos Direitos da Criança e do Adolescente e o Fundo Estadual dos Direitos da Criança e do Adolescente e dá outras providencias.(153). O Art. $2^{\circ}$ cria o CEDCA, órgão deliberativo e controlador das ações estaduais voltadas para a criança e o adolescente, A este órgão compete: (153)

1 - Formular a política estadual de atendimento dos direitos da criança e do adolescente, definido prioridades editando normas gerais e fiscalizando as ações de execução, observadas as linhas de ação e as diretrizes estabelecidas nos artigos 87 e 88 do Estatuto da Criança e do adolescente;

2 - Fixar critérios para a alocação de recursos destinados ao FECAD, através de planos de aplicação; ( redação dada pela lei no 12.974 de 27.121996 )

3 - Acompanhar a elaboração da proposta orçamentária do Estado, avaliado-a e indicando as modificações necessárias á consecução da política formulada

4 - Acompanhar o reordena mento institucional, propondo, sempre que necessário fazer modificações nas estruturas publicas e privadas destinadas ao atendimento dos direitos das crianças e dos adolescentes;

5 - Apoiar tecnicamente os Conselhos Municipais dos Direitos da Criança e do Adolescente, bem como a órgãos municipais e entidades não governamentais, objetivando a efetivação dos princípios, normas e diretrizes estabelecidas no Estatuto da Criança e do Adolescente;

6 - Aprovar e reformar seu regimento interno, por voto de no mínimo 2/3 de seus membros; Por tanto por lei é garantido que criem projetos e se faça valer o que na pratica esta prescrito, o profissional capacitado terá argumentos e saberá intervim para uma nova visão de valores culturais e essa necessidade é para que mude num todo. A prevenção perpassa os diversos serviços e políticas públicas com diferentes alcances e níveis específicos. A 
articulação das instituições é um pressuposto fundamental para efetivação do paradigma da proteção integral-Estatuto da Criança e do adolescente ( ECA ) (FERRARI,2002.PG.56 ).

Artigo $3^{\circ}$ "A criança e o adolescente gozam de todos os direitos fundamentais inerentes á pessoa humana, sem prejuízo da proteção integral de que trata esta lei, assegurando - lhes, por lei ou por outros meios, todas as oportunidades e facilidades, a fim de lhes facultar o desenvolvimento físico, mental, moral, espiritual e social, em condições de liberdade e de dignidade."

Artigo $4^{\text {o }}$ "È dever da família, da comunidade, da sociedade em geral e do poder público assegurar, com absoluta prioridade,a efetivação dos direitos referentes á vida,á saúde ,á alimentação, á educação,ao esporte,ao lazer,á convivência familiar e comunitária. Parágrafo único. A garantia de prioridade compreende:

a) primazia de receber proteção e socorro em quaisquer circunstância;

b) precedência de atendimento nos serviços públicos ou de relevância pública;

c) preferência na formulação e na execução das políticas sociais públicas;

d) destinação privilegiada de recursos públicos,nas áreas relacionadas, com a proteção á infầncia e á juventude."

Artigo $5^{\circ}$ "Nenhuma criança ou adolescente será objeto de qualquer forma de negligência, discriminação, exploração, violência, crueldade e opressão, punido na forma da lei qualquer atentado, por ação ou omissão, aos seus direitos fundamentais". A seguir seguem as atribuições do conselho tutelar.

\subsection{Atribuições do Conselho Tutelar}

De acordo com o Guia pratico do Conselho Tutelar, lei 12.010/09, os Conselheiros possuem a atuação administrativa e sua função é executar o que está previsto constitucionalmente e reivindicar na prática as políticas públicas de proteção a infância e a juventude, pois suas competências legais restringem se ao Poder executivo e não ao Poder Judiciário, não lhes são permitido a determinação de fazer cumprir ou punir quem infligir as leis. O seu papel como zelador dos direitos e deveres do ser infante, é apoiar e desenvolver requisições para os serviços públicos desde público. Ainda segundo o Guia não há uma formação para este órgão, para atuar no conselho tutelar deverá ter interesse, qualificação e passar por capacitação continua para exercer a função. A cada três anos é aberta concorrência 
publica para a candidatura à função de conselheiro, a previsão para o mandato é de três anos, com direito a recondução do mesmo (6 anos).

Cabe ao Conselho Tutelar tomar certos procedimentos após a denúncia, como: Apuração dos fatos denunciados, aconselhamento, encaminhamento as autoridades competentes para a aplicação das medidas de proteção vigente (ECA), a criança e ao adolescente e se preciso for médicos para uma melhor precisão de diagnósticos dos casos de agressão física, e são feitos relatórios desses casos mais relevantes e encaminhado a promotoria publica e a vara da infância e juventude.

Art.136. São atribuições do Conselho Tutelar

I - Atender as crianças e adolescentes nas hipóteses previstas nos art.98 e 105, aplicando as medidas no art. 101, I a VII;

II - atender e aconselhar os pais ou responsável, aplicando as medidas previstas no art. 129 I a VII;

III - promover a execução de suas decisões, podendo para tanto:

a) Requisitar serviços públicos nas áreas de saúde, educação, serviço social, previdência, trabalho e segurança;

b) Representar junto a autoridade judiciária nos casos de descumprimento injustificado de suas deliberações.

IV - encaminhar ao Ministério Publico noticia de fato que constitua infração administrativa ou penal contra os direitos da criança ou adolescente;

V - encaminhar á autoridade judiciária os casos de sua competência;

VI - providenciar a medida estabelecida pela autoridade judiciária, dentre as previstas no art. 101, de I a VI, para o adolescente autor de ato infracional;

VII - expedir notificações;

VII - requisitar certidões de nascimento e de óbito de criança ou adolescente quando necessário;

IX - assessorar o Poder Executivo local na elaboração da proposta orçamentária para planos e programas de atendimento dos direitos da criança e do adolescente;

$\mathrm{X}$ - representar, em nome da pessoa e da família, contra a violação dos diretos previstos no art. 220, 3, inciso II, da Constituição Federal;

Essa nova concepção de direitos e deveres para com o ser infante nos remete a questionar se a pratica condiz com a lei,, o que se percebe é a impotência dos conselheiros 


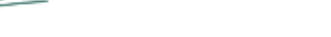

v. 11, n. 2,2015

diante a realidade do espaço em que atuam, um contexto social que requer reflexão sobre medidas remedi ativas mais eficazes em relação ao publico envolvido.

Neste contexto é relevante ressaltar a violência contra mulheres, sabe se que a lei de $\mathrm{n}^{\circ}$ 11.340 Maria da Penha, de 2006 ajudou muitas vítimas de agressões nos últimos anos e que é de suma importância que haja denúncias, a mulher como a criança antes não eram vistos, foram ao longo da história ganhando espaço e se integrando como parte importante na sociedade, mas por serem frágeis e vulneráveis, são as principais vítimas de abusos físicos , psicológicos e sexuais.

\section{OBJETIVOS}

A presente investigação foi de natureza descritiva e possuía como objetivo analisar as ações, limites e os obstáculos vivenciados no cotidiano dos profissionais atuantes do conselho tutelar na cidade de Jataí - Goiás.

Verificar como são os procedimentos do Conselho Tutelar diante dos fatos e casos atendidos, quais os órgãos que os apóiam e como o ECA Estatuto da Criança e Adolescente os aparam diante da lei, e se as mesmas são eficazes diante da realidade que os mesmos contemplam no cotidiano.

\section{METODOLOGIA}

\subsection{Participantes}

Os participantes foram dois dos cinco integrantes do Conselho Tutelar de Jataí, Goiás no ano de 2012. Entrevistou-se dois devido a disponibilidade destes em participar do estudo. Um participante era do sexo masculino, com graduação em Geografia e outro feminino possuía faculdade de Pedagoga com especialização em Educação Infantil. Os dois possuíam 31 e 32 anos de idade respectivamente.

\subsection{Procedimentos para a coleta de dados}

A entrevista ocorreu em dois momentos diferentes na sede do Conselho, e os mesmos em torno de 47 minutos cada, fomos interrompidos por diversas vezes, devido a 
telefonemas de casos a serem resolvidos e documentos a serem assinados. Exceto por tais interrupções, a coleta de dados transcorreu tranqüila.

\subsection{Instrumento de coleta de dados : entrevista estruturada}

Foi utilizado como coleta de dados uma entrevista semi-estruturada com 5 questões:

1 - Qual a sua atuação junto ao Conselho Tutelar de Jataí, Goiás, o que você faz, quais são suas atividades?

2 - Quais as dificuldades e/ou obstáculos que você encontra nas suas atividades diárias junto ao Conselho Tutelar?

3 - O que você sugere a fim de melhorar a sua atuação, e no geral trabalho?

4 - O que acha que poderia ser feito para diminuir os índices de violência contra crianças e adolescentes?

5 - A equipe realiza algum tipo de atividade voltada para a escola?

\section{RESULTADOS E BREVE DISCUSSÃO}

A presente investigação foi de natureza descritiva e possuía como objetivo analisar as ações, limites e os obstáculos vivenciados no cotidiano dos profissionais atuantes do conselho tutelar na cidade de Jataí - Goiás. As respostas dos participantes foram analisadas de maneira qualitativa tendo por base a revisão de literatura.

A primeira questão investigou qual a atuação do conselheiro tutelar da cidade de Jataí, Goiás, suas tarefas e atividades. Resposta conselheiro M 31: "Minha missão é preservar a integridade física, mental e intelectual da criança e do adolescente. Enquanto conselheiro, nos temos a ação direta com a população recebendo as denuncias e averiguando as, trabalho na elaboração de relatórios dos casos, atendimento direto ao publico por via de aconselhamento, encaminhamento a autoridades competentes dos casos considerados mais graves. Porque as ações de políticas públicas são realizadas pelo Conselho Municipal dos Direitos da Criança e do Adolescente'. 
Resposta conselheira L 42: "Conselheira, para com as famílias, crianças e adolescentes $e$ orientação. As Atividades: relatórios, palestras, visitas, aconselhamento, ocorrências menores infratores, fiscalização em bancas de revistas, creches, abrigos, CMEIS e escolas".

As duas respostas vão de encontro ao que é previsto no Guia pratico do Conselho Tutelar, lei 12.010/09. Os conselheiros possuem bastante clareza sobre como deve ser sua atuação junto as crianças e adolescentes da região. Na entrevista realizada junto aos conselheiros, chamou a atenção duas ações citadas pela conselheira L, que o M não colocou em sua resposta a fiscalização de materiais impróprios para a criança e adolescente exposto em bancas da cidade e a ação de palestras oferecidas por eles quando requisitadas. Interessante ressaltar que, a palavra usada na resposta pela Conselheira $\mathrm{L}$, de acordo com o Estatuto da Criança e do adolescente ( ECA ) o termo “ menor” não mais é citado no mesmo.Ainda de acordo com o ECA os conselheiros intervêm com suas ações e utilizam das pretensões da lei prescritas no Estatuto.

A segunda questão investigou quais as dificuldades e/ou obstáculos que o conselheiro encontra em suas atividades diárias junto ao conselho tutelar?

Resposta M 31: "Desvalorização profissional, a profissão nos expõem a riscos, diante das leis somos limitados ao atendimento,aconselhamento e encaminhamento dos casos atendidos,e devido a este fator a população não entendem as atribuições do Conselho Tutelar, as sua formas de ações, a sociedade cobra ações imediatas, em alguns casos não nos é permitido a autonomia para resolve-los, pois a todo um processo de encaminhamento aos órgãos competentes".

Resposta L 42: "São vários, falta de compreensão da função dos conselheiros, casos limitados, são bastante limitados, barrados, falta de aceitação das famílias".

As respostas de M e L são semelhantes, ambos agregam os mesmos fatos e temores em seus discursos. Percebe - se que não ha esclarecimentos de suas ações e deveres para com a criança e o adolescente junto ao público em geral e das famílias em relação as funções dos conselheiros. Tal desconhecimento os constrangem e as cobranças por ações imediatas se deve a este desconhecimento das legislações que norteiam suas funções. Desde que foi criado, não foi delegado ao Conselho Tutelar qualquer tipo de formação, o Guia Prático do Conselho Tutelar somente intitula ao mesmo a vocação, e a capacitação continuada por meio de cursos esporádicos de pouca duração. De acordo com o conselheiro M, já estão implantados nas grandes metrópoles do país em algumas Universidades, cursos de duração de 
2 anos para o Conselho Tutelar, contudo tal realidade ainda não alcançou o município dos interior do país como Jataí.

A terceira questão verificou se os conselheiros tinham alguma sugestão para a melhoraria da sua atuação, e no geral trabalho.

Resposta M 31: "Mais cursos para a capacitação profissional do Conselho Tutelar, mais componentes. A disponibilidade imediata na sede do Conselho Tutelar de psicólogos de tempo integral, para um atendimento eficaz no nosso cotidiano, o espaço físico adequando e melhores equipamentos, para um melhor atendimento".

Resposta L 42: "Sugestão de aspecto físico, mão de obra, funcionários, outro conselho, são poucos para tanta demanda, no aspecto moral, psicólogos e mais cursos de capacitação par nós conselheiros, necessitamos de mais apoio enquanto a nossa capacitação.

Percebe-se nas falas, que ambos sentem as mesmas necessidades diante da realidade que atuam, a estrutura oferecidas a eles não os satisfazem e nem lhes dão suporte para um trabalho de qualidade, sentem o desamparo do sistema para com o desenvolvimento de seu trabalho. De acordo com os relatos verbais dos integrantes do Conselho Tutelar, os mesmos em vários casos ficam limitados à resolução dos problemas sem autonomia. Atendem, em sua maioria, a um público familiar desestruturado e negligente com suas crianças, e devido a fatores sociais como, o desemprego, abandono de incapaz, vícios, higiene, alimentação, e tantos outros, a estes somente lhes imputam a ação do aconselhamento. Segundo o Guia Pratico do Conselho Tutelar, o Conselho Tutelar é um órgão autônomo, contudo porém vinculado administrativamente ao município, ele é subordinado as políticas publicas de atendimento as crianças e adolescentes do mesmo, e depende de vários fatores de cunho político e econômico para adquirirem suporte almejados por eles, para uma melhor qualificação do seu trabalho. Vale frisar que, parece não haver suporte técnico nem político para amparar e melhorar a atuação deste profissionais.

A quarta pergunta investigou o que tais profissionais achavam que poderia ser feito para diminuir os índices de violência contra crianças e adolescentes na cidade de Jataí Goiás.

Resposta M 31: "Orientação para pais e a sociedade em geral, por via de palestras e cobrança rigorosa da lei para com os responsáveis e instituições que lidam diariamente com crianças e adolescentes". 
Resposta L 42: "Prevenção nas escolas e nas casas, com palestras, aconselhamento e encaminhamento para o Amor Exigente, sempre que necessário".

A partir das respostas percebemos que ambos divergem somente no requisito da cobrança da lei citada por M, pelo Estatuto da criança e do Adolescente, está previsto no Titulo III da Prevenção, é dever de todos prevenirem, qualquer ameaça ou violação dos seus direitos. Para os conselheiros as palestras, aconselhamento e a parceria com instituições para auxiliá-los, são medidas eficazes, que contribuirão para uma melhor prevenção para com a criança e adolescente diante dos problemas que os mesmos poderão se confrontar.

A quinta pergunta verificou se a equipe realiza algum tipo de atividade voltada para a escola. no sentido de uma prevenção.

Resposta M 31:" Sim. Orientamos sempre que requisitados, por via de ofícios, palestras.

Resposta L 42:"Existe sim. Sempre que nos requisitam vamos, atendemos não somente as escolas públicas, mas também as privadas."

Os dois conselheiros relatam que existe um trabalho para o ambiente escolar, não somente nas escolas públicas, mas também nas instituições privadas. O profissional da educação deverá saber identificar os sinais e sintomas característicos de violência que o leve a denunciar situações de maus tratos as crianças e adolescentes. È importante dizer que os valores são construídos culturalmente na sociedade, e a escola tem um papel importantíssimo para a transformação e evolução dos mesmos, ela é um complemento da família na formação do individuo. Diante de todas as questões levantadas esta pesquisa é relevante porque pretende auxiliar e fazer com que o educador, procure se aprofundar nas medidas e métodos que os levem a identificar sinais de maus tratos, e com isso a criança e o adolescente possam está, preparados para se defenderem denunciando seus agressores.

É dever ao conselheiro tratar de assuntos referentes em lei, que previne, e garante na sua integridade todos os deveres e direitos da criança e do adolescente prescrito no Estatuto da Criança e do adolescente.

\section{CONSIDERAÇÕES FINAIS}

A pesquisa em seu processo trás um diagnóstico de que os casos atendidos por parte dos conselheiros, são mediadas em sua ação pelo Guia Pratico do conselho Tutelar, Estatuto da Criança e do Adolescente e cursos esporádicos que lhes são oferecidos pelo 
Estado e município. A impressão que se tem é que os mesmos tem que esclarecerem cotidianamente a posição que ocupam na intervenção dos conflitos familiares, e fica claro para nós que o papel que ocupa na sociedade é o de intermediador.

Os dados apresentados neste trabalho, de acordo com a pesquisa, nos revelam que as crianças e os adolescentes do município de Jataí, Goiás, sofrem com a violência. É seus direitos e deveres que deveriam ser assegurados pelo Estatuto da Criança e do Adolescente ainda estão distantes de serem cumpridos. Politicamente as estruturas físicas e econômicas do sistema ainda não suprem as demandas das políticas públicas elaboradas para o bem estar integral deste público. De fato, na prática existem falhas segundo o contexto em que o Conselho Tutelar atua, os conselheiros devem saber lidar com problemas emergenciais e para tanto precisam ser desenvolvidas formas sistematizadas de transmissão, uma vez que a duração do seu trabalho somente pode ser realizado entre 3 anos e 6 anos no caso de ser reeleito para o cargo.

Existe a necessidade também de uma capacitação para tais profissionais. Tal idéia envolve uma formação apropriada e experiência prática para uma melhor contribuição em suas ações no cotidiano, para o enfrentamento da realidade social em que atuam os conselheiros tutelares.Futuras pesquisas podem ser desenvolvidas a respeito deste tema, ampliando de maneira mais aprofundada a respeito da atuação, limites e possibilidades dos conselheiros tutelares em suas cidades.

\section{REFERÊNCIAS}

ARIÈS, Philippe. História Social da Criança e da Família. 2 ed. Rio de Janeiro: LTC, 1981.

BUENO, J.G.S. (1999). Educação Inclusiva: Princípios e Desafios. Mediação (Disponível na SME/RJ - Secretaria Municipal de Educação do Rio e Janeiro),1(1), 22-28.

Conselho Estadual dos Direitos da Criança e do Adolescente. Estatuto da Criança e do Adolescente, Lei Federal no 8069, de 13 de julho de 1990.Goiânia - GO. 2010.p.172.

BRASIL, Estatuto da Criança e do Adolescente. Normativas Internacionais. Conselho Nacional dos Direitos da Criança e do Adolescente. Brasília, DF: Conanda, 2002.

DALKA, C.A.Ferrari, Tereza.C.C.Vecina. O fim do silêncio na violência familiar:teoria prática. $3^{\circ}$ ed.Editora Agora.2002.p.09 á 131. 
FERRARI, M.; KALOUSTIAN, S. M. A importância da família. In: KALOUSTIAN, S. M. (Org.), Família brasileira: a base de tudo. 5.ed. São Paulo: Cortez : Brasília, DF: UNICEF, 2002.

MARQUES, João Benedito de Azevedo.Democracia, Violência e Direitos Humanos.São Paulo. $2^{\circ}$ ed.Editora Cortez.1992.p.102.

ODALIA, Nilo. O que é Violência. São Paulo.ed.brasiliense.1985.p.93.

LEI No 11.549, DE 16 DE OUTUBRO DE 1991. Cria o Conselho Estadual dos Direitos da Criança e do Adolescente e o Fundo Estadual dos Direitos da Criança e do Adolescente sancionada pela Assembléia legislativa do Estado de Goiás. 